\title{
A PSICOCINÉTICA DE JEAN LE BOULCH E O CONHECIMENTO DO CORPO NA EDUCAÇÃO FÍSICA
}

\author{
THE PSYCHOKINETICS OF JEAN LE BOULCH AND BODY KNOWLEDGE IN \\ PHYSICAL EDUCATION
}

\section{LA PSICOCINÉTICA DE JEAN LE BOULCH Y EL CONOCIMIENTO DEL CUERPO EN LA EDUCACIÓN FÍSICA}

\section{Christyan Giullianno de Lara Souza Silva*, Bernard Andrieu**, Terezinha Petrúcia da Nóbrega***}

Palavras chave: Psicocinética.

Corpo.

Epistemologia. Educação Física.

Keywords: Psychokinetics. Body. Epistemology. Physical Education.

Palabras clave: Psicocinética.

Cuerpo.

Epistemología. Educación Física.
Resumo: O presente ensaio apresenta o pensamento de Jean Le Boulch e suas ideias sobre a Psicocinética e o esquema corporal. Trata-se de um estudo teórico, apoiando-se nas obras do autor publicadas no Brasil e sua tese doutoral, defendida em 1960. Utilizamos também uma entrevista concedida à revista francesa Éducation Physique et Sport (EPS) (1983), além de outros trabalhos desenvolvidos por ele, tais como conferências, palestras e seminários. Com essa reflexão espera-se contribuir para a compreensão de suas ideias, em particular sobre o conhecimento do corpo na Educação Física.

Abstract: The present essay presents Jean Le Boulch's thinking and his views on psychokinetics and body schema. It is a theoretical study based on the author's works published in Brazil and his doctoral thesis defended in 1960. We also used an interview given to French magazine Éducation Physique et Sport - EPS (1983) as well as conferences, lectures and seminars. This reflection is intended to contribute to understanding his ideas, particularly about the body in the field of Physical Education.

Resumen: Este ensayo presenta el pensamiento de Jean Le Boulch y sus ideas sobre la psicocinética y el esquema corporal y la propiocepción. Se trata de un estudio teórico que se apoya en las obras del autor publicadas en Brasil y en su tesis doctoral, defendida en 1960. Utilizamos también una entrevista concedida a la revista francesa Éducation Physique et Sport - EPS (1983), además de otros trabajos desarrollados por él, tales como conferencias, conferencias y seminarios. Con esta reflexión se espera contribuir a la comprensión de sus ideas, en particular sobre el conocimiento del cuerpo en la Educación Física.
*Secretaria Municipal de Educação de Natal. Natal, RN, Brasil. Email: cglsouzasilva@gmail.com

**Bernard Andrieu. Université Paris Descartes. Paris, França. Email: bernard.andrieu@ parisdescartes.fr

${ }^{* * *}$ Universidade Federal do Rio Grande do Norte. Natal, RN, Brasil. E-mail: pnobrega68@gmail.com

Recebido em: 31-07-2018 Aprovado em: 30-09-2018

DOI: https://doi.org/10.22456/1982-8918.85386 (c) (1) (3) Licence 


\section{INTRODUÇÃOO}

Jean Joseph Le Boulch nasceu em 28 de janeiro de 1924, em Lambézellec (atualmente anexada à cidade de Brest), na França. Formado em Educação Física, Psicologia e Medicina, iniciou sua carreira como professor em 1947, no CREPS (Centre Regional d'Education Physique et Sportive), situado na cidade de Dinard, local onde lecionou até 1969, período em que se iniciam suas críticas à educação francesa em meio a diversos conflitos, interesses políticos partidários, do governo, de doutrinas políticas e os debates sobre o programa nacional de educação. No que se refere à Educação Física, encontrava-se envolto às novas orientações políticas conflitantes sobre os métodos, acompanhadas da "libertação" da França após a guerra' (LE BOULCH, 1983, 1983b, 2008).

Essas orientações já vinham definindo-se no século anterior, desde a segunda metade do século XIX, quando a ginástica foi integrada à ideia de educação, voltada ao desenvolvimento social e à formação de homens completos. A Educação Física passa a ser organizada não apenas para militares, mas para a população em geral, com fundamentações teóricas construídas em torno do corpo anatômico e fisiológico e baseadas em estudos da Biologia, Fisiologia e Medicina; bem como a propagação de ideais fundadas em uma moral eugenista que contribuíram para difusão dos exercícios físicos na França e forneceram os fundamentos da Educação Física no século seguinte (SOARES, 2004).

As metodologias ginásticas e o uso do esporte para fins ideológicos caracterizavam-se pelo entendimento biológico e eficácia do corpo com vista à aptidão para o trabalho. Sob uma ótica política, esses foram alguns dos fatores que impulsionaram os questionamentos de Jean Le Boulch e a formulação da Psicocinética. Le Boulch dedicou-se à formação e publicação de trabalhos para futuros professores de Éducation physique et Sportive'2, contribuindo na área de Educação Física da escola primária e do ensino fundamental. Nesse contexto, apresentou 0 livro A Educação pelo movimento, editado em 1966. Nesse livro, Le Boulch dirige-se não apenas aos professores primários e da educação fundamental, mas também aos que trabalham com a educação e reeducação de crianças. Nele são postos os princípios fundamentais da Teoria Psicocinética, apresentando-a não como um novo método de Educação Física, mas como uma teoria geral do movimento. Desse modo, buscava-se uma reflexão mais aprofundada e ampla para a Educação Física e para o estudo do movimento humano, baseados em estudos diversos, não apenas nas Ciências Biológicas, mas considerando também as Ciências Humanas. Notase no trabalho de Le Boulch o entrelaçamento desses estudos não apenas como uma estratégia de ensino, relacionando teoria científica e prática pedagógica (LE BOULCH, 1983).

Jean Le Boulch estudou em Rennes, onde especializou-se em reabilitação funcional e trabalhou no Hospital Universitário com reabilitação psicomotora, aprofundando, assim, seus estudos em Biologia, Fisiologia e Psicologia, mas sempre interessado na formação de professores, no campo educativo e nas questões do ensino em Educação Física, sua primeira formação (LE BOULCH, 1983b). Sua tese de doutorado em Medicina foi defendida em 8 de fevereiro de 1960. Professor de Educação Física, ele decide apoiar-se em bases experimentais para estudar o movimento, considerando: "[...] o ato motor não somente em seu aspecto efetor

1 No período após a Segunda Guerra Mundial, a Educação Física na França encontrava-se marcada por conflitos entre os métodos que orientavam essas práticas: método natural de Georges Hébert, o método higienista sueco e o método esportivo, estimulado pela obra de Pierre de Coubertin, criada pelos Jogos Olímpicos (Le Boulch, 2008).

2 Nomenclatura que designa o Professor de Educação Física na França. 
ou somato-orgânico, mas igualmente em seu aspecto perceptivo" (LE BOULCH, 1960, p. 3). A originalidade epistemológica de Le Boulch foi o fato de ter aplicado o modelo piagetiano de acomodação dos esquemas às respostas sensório-motoras na ação, destacando a análise do esquema corporal e das sensações cinestésicas chamadas por ele de "inteligência motriz" (LE BOULCH, 1960, p. 23). De fato, tratou-se de uma inovação científica e metodológica que merece ser considerada no cenário epistemológico e pedagógico da Educação Física.

Le Boulch trouxe os conhecimentos da psicomotricidade para a Educação Física, que se mostraram incompatíveis com as instruções francesas, haja vista que a psicomotricidade nasceu sob a forma de reeducação psicomotora em clínicas de neuropsiquiatria infantil, baseada nos discursos médicos e, mais especificamente, neurológicos fortemente marcados pelo paralelismo psicofisiológico do sistema nervoso. Neste período, valendo-se dos seus vários anos de estudos e debates sobre a Educação Física na França e buscando promovê-la sob uma ótica psicomotora, ele viajou a várias regiões de seu país, promovendo seminários, buscando informar os professores de Educação Física sobre essa nova possibilidade de atuação. Mas, apesar de seus esforços, ele não obteve êxito, haja vista a grande resistência dos professores que estavam de acordo com as orientações oficiais. Buscou também atuar junto às instituições oficiais da Administração, mas também não conseguiu bons resultados, pois, segundo os inspetores, sua ideia encontrava-se em contradição com as instruções oficiais (LE BOULCH, 1983b).

Le Boulch criticou a Educação Física na forma como era instruída na França naquele período, em especial sua obediência às considerações ideológicas e alternando segundo anseios políticos. Seu entendimento era 0 de que havia uma incompatibilidade de suas pesquisas com a instruções legais. Por essa razão, passou a dedicar-se também a outras formações acadêmicas; mas sem abandonar suas ações na área de formação de professores, seja em seus trabalhos experimentais, seja no aprofundamento do campo vasto e disperso que era o movimento humano.

Le Boulch abordou a compreensão da motricidade humana e a sua complexidade, defendeu o desenvolvimento e a aprendizagem da pessoa através do movimento do corpo e de sua expressão motriz; bem como considerou a história da Educação Física e do Esporte na França. Ele também se interessou pelo conhecimento elaborado em áreas como a Pedagogia e a Psicologia para apoiar seus estudos sobre a experiência do movimento do corpo como vetor do desenvolvimento do ser humano de modo geral e das crianças em particular. Le Boulch criou a Psicocinética, compreendida como ciência do movimento humano, cujas características principais passamos a delinear neste artigo.

\section{A PSICOCINÉTICA DE JEAN LE BOULCH}

Buscando uma compreensão mais ampla sobre o movimento humano e desejando unir conhecimentos sobre o assunto, Le Boulch dedicou-se a formações em outras áreas do conhecimento. Ele criticava a formação em Educação Física, considerando-a enciclopédica e superficial sob muitos aspectos, em especial no tocante aos aspectos fenomenológicos do corpo, aos aspectos expressivos e afetivos do movimento. Ele empreendeu estudos na área da Medicina, aprofundando-se na Biologia, imprescindível para as ciências do movimento humano. Considerava que era necessária uma compreensão mais ampla do movimento e 
então graduou-se também em Psicologia. Somente depois de ter obtido o seu terceiro diploma, percebeu que se continuasse nessa dinâmica, teria que se graduar em Sociologia e ainda assim não conseguiria ser suficiente (LE BOULCH, 1987; 1995).

Minha formação inicial é a de professor de educação física. Esta formação era, na época, e continua sendo cada vez mais essencialmente técnica, fundada sobre a aprendizagem de um certo número de gestos codificados - técnicas esportivas. Superposta a essa enumeração gestual, um ensino de anatomia, de fisiologia, de psicologia, de sociologia, interessante em si, mas na maior parte do tempo inaplicável ao terreno considerado como movimento, pois tratado por fundamentalistas que frequentemente ignoram os problemas concretos a que estarão confrontados aos professores de educação física. Insatisfeitos por essa formação enciclopédica e, contudo, superficial sob muitos aspectos, alguns deles demandam estudos em medicina; outros de psicologia ou de filosofia. Pessoalmente comecei pela medicina; esta formação de 6 anos permite aprofundar certas áreas da Biologia, fundamentais em ciências do movimento; porém ao tempo de quanto tempo perdido no estudo e na prática de técnicas sem o interesse direto para 0 assunto que me atraía. Sendo essa formação insuficiente para abordar cientificamente o estudo do movimento, empreendi uma formação em psicologia, que me parecia indispensável (LE BOULCH, 1987, p. 9-10).

Le Boulch decidiu desenvolver uma teoria cujo aspecto central prioriza o movimento, buscando uma educação global do ser humano, uma educação perceptiva e baseada no conhecimento do corpo. Ele buscava definições mais precisas sobre a necessidade e importância do movimento no desenvolvimento do ser humano, premissas que a Educação Física até então negligenciava. Para ele havia a necessidade de superação da "doutrina esportiva" da época (LE BOULCH, 1983; 1983b; 2008).

A Psicocinética é uma teoria geral do movimento que conduz ao enunciado de princípios metodológicos que permitem encarar sua utilização como meio de formação [...] utiliza o movimento humano para educar. Várias ciências [...], interessam-se [...] por esse objeto de pesquisa. Mas para nenhuma [...] o estudo do movimento representa um aspecto central (LE BOULCH, 1983, p.7; 1987, p.11).

A Teoria Psicocinética e os estudos apresentados pelo autor ensejam muitas reflexões. Suas ideias gerais e os conceitos por ele abordados foram difundidos em muitos países onde desenvolveu diversos trabalhos, ministrou cursos e conferiu palestras em escolas e universidades, dentre eles: Canadá, Argentina, México, Peru, Espanha, Itália e Brasil. Especificamente no Brasil, observamos nas discussões da Educação Física nas décadas de 1970 e 1980, uma mudança de pensamento, principalmente, no âmbito da educação da criança e no campo da educação formal escolar, onde suas ideais foram trazidas por diversos autores e apresentadas como possibilidade de educação a partir do corpo e do movimento humano.

Le Boulch $(1977 ; 1983)$ apresenta alguns dos pressupostos de sua teoria, buscando enfatizar a importância do movimento para o ser humano. A Psicocinética está ligada a uma filosofia da educação. Nesse sentido, quando se fala em educação, supõe-se ter um objetivo para a finalidade da ação educativa. Entende-se, no âmbito da educação pelo movimento, 0 homem como um ser social, que se educa na relação de comunicação com outrem, como um ser da coletividade. Assim:

Educar um homem como um ser social é ir além de apenas adaptá-lo a esta sociedade, é torná-lo apto a superar as mudanças sociais que decorrerão necessariamente da evolução das revoluções dos homens entre si. Essa 
plasticidade de adaptação e essa possibilidade de nova discussão das normas admitidas por este ou aquele tipo de organização social e de cultura implica que a socialização seja um processo ativo consciente da necessidade de engajamento social, e não uma simples conformidade ou simples habituação e essa sociedade (LE BOULCH, 1987, p.31).

Considerando que a Psicocinética tem sua ação voltada para as atividades corporais e ao movimento humano, seu objetivo seria atingido na medida em que 0 ato motor seja compreendido como uma ação significativa para o ser humano como um todo em relação ao seu entorno. Na Psicocinética, o objetivo educacional é favorecer o desenvolvimento humano, permitindo ao homem situar e agir no mundo por meio do conhecimento e aceitação de si; um melhor ajustamento da conduta, desenvolvendo autonomia e responsabilidade no âmbito social.

A Psicocinética apoia-se numa concepção não dualista, problematizando a dicotomia corpo e espírito nos processos educativos. Esse entendimento parte da uma possibilidade diferente de abordar o corpo e o movimento humano, não unicamente através dos processos clássicos, ou seja, da consideração do corpo humano como um mero objeto, dissecado em partes, analisado de modo fragmentado ou estudado sob um único ponto de vista seja anatômico, fisiológico, psicológico ou social. Outro aspecto a destacar é o fato de que na Psicocinética consideram-se, sobremaneira, a expressividade e os gestos do corpo nas mais diversas possibilidades, como uma manifestação do corpo presente no mundo. Desse modo, emoção, afetividade e expressividade são inerentes ao corpo e ao movimento humano (LE BOULCH, 1987).

Outro ponto a se destacar é a compreensão da totalidade corporal que se apoia na noção de "estruturação recíproca". Esse princípio baseia-se nos trabalhos de Mucchielli ${ }^{3}$, Wallon ${ }^{4}$ e Merleau-Ponty ${ }^{5}$, referindo-se à relação vivida entre o homem e o mundo, o homem percebendo ele mesmo e o homem percebendo o mundo de forma recíproca. Tal compreensão enfatiza a experiência vivida, assim, por exemplo, no aprendizado das crianças, e de forma mais geral do ser humano, essa experiência tem papel fundamental. Esse princípio tem por base ainda os trabalhos de John Dewey ${ }^{6}$, Freinet ${ }^{7}$ e Mucchielli ${ }^{8}$, preconizando que a experiência e a didática do professor não substituem a experiência vivenciada pela criança. Será através de sua experiência pessoal que a criança compreenderá e dominará uma nova situação, cabendo ao professor proporcionar as condições para a experiência das crianças.

Outro aspecto importante nos questionamentos de Jean Le Boulch em relação à Educação Física refere-se à importância do fator humano e dos fenômenos sociais na formação do indivíduo. O meio onde cresce uma criança é primordial, não dependendo apenas das especificidades biológicas, mas do meio social e humano em que vive. Desse modo, destacase 0 valor do papel do educador, estabelecendo uma relação adequada e empreendendo o trabalho em grupo com propósito de socialização.

\footnotetext{
3 "O mundo e o eu se constituem correlativamente e se estruturam reciprocamente" (MUCCHIELLI apud LE BOULCH, 1983, p.18)

4 "Um gesto, ao mesmo tempo em que modifica o meio, modifica aquele que o executa" (WALLON apud LE BOULCH 1983, p.18).

5 "A hipótese de uma consciência fechada em sua interioridade e gerando o comportamento como um navegante com seu navio deve ser eliminada" (MERLEAU-PONTY apud LE BOULCH, 1983, p.18).

6 "Não podemos adquirir ideias, sentimentos, técnicas, senão vivendo-os" (JOHN DEWEY apud LE BOULCH 1983, p.19).

7 Referindo-se à prática pessoal "tatear experimental" (FREINET apud LE BOULCH, 1983, p.19).

8 "Na situação real, as variáveis e seus efeitos estão mergulhados na massa das variáveis ou das influências parasitas e, em função disso, são muitas vezes pouco aparentes" (MUCCHIELLI apud LE BOULCH, 1983, p.19).
} 
Para Le Boulch, a Psicocinética, valendo-se da prática de jogos e atividades de livre expressão (jogos dramáticos, jogos de imaginação, jogos a partir de temas musicais), conduz à possibilidade de "aprendizagem rápida", pensada a partir da percepção do corpo, respeitando o desenvolvimento da criança, rejeitando em sua proposta a aprendizagem técnica. Sendo assim, as crianças terão vivências com objetos de forma global, através de atividades espontâneas, possibilitando variar e ajustar as vivências e refiná-las posteriormente, tanto para utilização no lazer, como no plano profissional.

Partindo dos pressupostos da teoria, parece-nos claro afirmar que a Psicocinética, considerando-se a época na qual foi pensada, já apresentava posições que ensejam reflexões importantes sobre o corpo e o movimento que ainda hoje necessitam de aprofundamentos teóricos e metodológicos no campo da Educação Física.

\section{CORPO EM LE BOULCH}

A educação dos fatores do movimento coloca o acento sobre o domínio do corpo compreendido em termos de unidade psicomotora. Assim, as condutas motoras devem ser observadas em relação com as condutas do ser por inteiro (LE BOULCH, 1961): "a conduta motriz é indissociável dos fenômenos mentais: intelectuais, emocionais e dos fenômenos neurovegetativos" (LE BOULCH, 1961, p. 12).

Nesse contexto, a noção de esquema corporal será relevante para a organização da ação motriz. "O esquema corporal supõe a percepção imediata de não importa qual parte do corpo integrada em um conjunto global e em ligação com o mundo exterior" (LE BOULCH, 1961, p. 18). Inicialmente inconsciente, o esquema corporal permite o ajuste postural e motor que corresponde ao tratamento das informações proprioceptivas.

Assim, faz-se necessário compreender essa globalidade como sendo uma totalidade dinâmica da unidade psicomotriz. Para tanto, é preciso "considerar o movimento não como uma forma 'em si' cuja natureza seria elucidada por uma descrição mecânica, mas como uma manifestação 'significante' da conduta humana" (LE BOULCH, 1971 p. 45). Nesse sentido, a noção de intenção encontra-se profundamente ligada ao corpo e ao espírito como unidade. Para o autor, a Psicocinética, em sua intencionalidade motriz, rompe com o dualismo corpo e espírito, tal como já haviam demonstrado as teses fenomenológicas da percepção (MERLEAUPONTY, 1945). Para a fenomenologia de Merleau-Ponty, a intencionalidade do movimento é uma forma original de ser e estar no mundo por meio da expressividade do corpo no mundo (NÓBREGA, 2014).

Considerando o conceito de corpo próprio apresentado por Le Boulch, temos que "0 organismo que nos dão a conhecer ao mesmo tempo a fisiologia e a psicologia, não é o corpoobjeto estudado pela fisiologia clássica, mas o corpo de um 'ser-situado-corporalmente-nomundo', isto é, um 'corpo-próprio"' (LE BOULCH, 1987, p.20). O esquema corporal apresenta-se no contexto da Psicocinética de Jean Le Boulch como uma forma de imagem do corpo, melhor dizendo, como um conhecimento de si ou uma consciência do próprio corpo. Para Collinet (1999), a Psicocinética delimita objetivos a partir dessa noção de esquema corporal, como, por exemplo, desenvolver harmoniosamente e minimizar os problemas eventuais na constituição do corpo; desenvolver a percepção correta do corpo de modo a assegurar uma motricidade equilibrada que permita uma via relacional eficaz; visar a manutenção e regulação postural. 
Gleyse (1995) e Collinet (1999) apresentam críticas importantes ao pensamento de Le Boulch. De acordo com Gleyse (1995), a partir dos anos 1960 o discurso da Psicomotricidade ou Psicocinética na Educação Física submeteu o corpo ao psiquismo, sem de fato romper com o dualismo tradicional entre corpo e espírito ou o corpo e a alma, sendo a motricidade considerada como o vetor de tal lógica. Para o autor, Le Boulch, assim como outros psicomotricistas daquela época, apoia seus trabalhos sobre uma psicologia marcadamente neurológica, o que reduz a compreensão da experiência social ou histórica no entendimento da Educação Física e do corpo (GLEYSE, 1995).

Collinet (1999) aborda o trabalho de Le Boulch sob vários aspectos, incluindo a concepção fenomenológica de corpo utilizada por ele. Para ela, os estudos fenomenológicos do corpo na Psicocinética "[...] servem de justificativa à prática psicomotora e permitem a concepção de diferentes relações do indivíduo com seu corpo" (COLLINET, 1999, p. 44). Eles concebem ainda uma relação estreita entre o indivíduo e o meio, "[...] postulando a existência de idas e vindas, já que o sujeito e o mundo são duas entidades indissociáveis" (COLLINET, 1999, p. 44).

A autora diz ainda que as pesquisas de Le Boulch mostram que a ligação entre 0 corpo e o espírito se traduz pela noção de intencionalidade, frequentemente apresentada como a descoberta principal da fenomenologia. Esses aspectos são considerados relevantes, mas Collinet (1999) aponta algumas falhas na concepção da Teoria Psicocinética, dentre elas destaca a relação entre a Psicomotricidade como método de reeducação e sua influência ante a Psicocinética, que na sua visão é um método de Educação Física, não conseguindo se distanciar dos pressupostos da Psicomotricidade, ou seja, permanece a imprecisão encontrada entre uma e outra proposta no tocante aos aspectos da reeducação e da educação em seus aspectos mais amplos relacionados ao contexto social e histórico.

Outro ponto criticado por Collinet (1999) diz respeito ao "uso" ou uma "instrumentalização" do movimento através de seus exercícios e práticas para desenvolver habilidades ou a consciência do movimento no lazer, no esporte, na aprendizagem laboral como desencadeadores de mudanças de hábitos ou estilos de vida. Esses aspectos também já foram observados no Coletivo de Autores (SOARES et al., 1992), ao indicarem a ausência de uma reflexão social e histórica no trabalho de Jean Le Boulch.

O terceiro ponto crítico apresentado por Collinet (1999), e que aqui destacamos, encontra-se mais ligado à orientação filosófica utilizada na Psicocinética. Segundo Collinet (1999), a falta de aprofundamento da fenomenologia de Merleau-Ponty ou dos estudos de Buytendijk na teoria Psicocinética e na Psicomotricidade reduzem a compreensão da percepção do corpo e do movimento ao paralelismo psicofisiológico, mantendo-se o dualismo das atividades motoras e cognitivas. Nesse sentido, Nóbrega, Mendes e Gleyse (2016) afirmam que Le Boulch recorre a Merleau-Ponty para afirmar a ligação entre o corpo e a intencionalidade. "No entanto, a orientação filosófica dada pela fenomenologia é abandonada em proveito de conceitos científicos de ordem psicofisiológica (NÓBREGA, MENDES, GLEYSE, 2016, p.231). Os autores reconhecem que o trabalho de Le Boulch contribuiu para a emergência de novas abordagens sobre o corpo na Educação Física em vários países, como Brasil, Argentina, Portugal, França. No entanto, esses estudos carecem de aprofundamento sobretudo no que diz respeito à abordagem fenomenológica do corpo.

A partir dessas referências destaca-se a centralidade do corpo na obra de Jean Le Boulch e, ao mesmo tempo, reconhecem-se os limites de sua compreensão e a necessidade 
de aprofundamentos seja no campo dos estudos culturais e históricos como lemos nos trabalhos realizados por Gleyse (1995) e Soares et al. (1992), seja no campo das abordagens fenomenológicas (ALMEIDA; BRACHT; GHIDETTI, 2013).

\section{AS IDEIAS DE LE BOULCH NO BRASIL}

Em 2008, foi lançada no Brasil a última obra de Le Boulch traduzida para o português, intitulada $O$ corpo na escola no século XXI: Práticas corporais, publicada originalmente na França em 1998, como resultado de 40 anos das suas pesquisas. Além dessa obra, outras seis foram traduzidas e lançadas no Brasil: Introdução à Psicocinética (1977); O desenvolvimento psicomotor: do nascimento até 6 anos (1982); A educação pelo movimento: a psicocinética na idade escolar (1983); Rumo a uma ciência do Movimento Humano (1987); Educação psicomotora: a psicocinética na idade escolar (1987) e Curso de Psicomotricidade (1983a) baseado nas apostilas do curso de Psicomotricidade proferido por ele na Universidade Federal de Uberlândia em 1978, que também compõem o acervo dos trabalhos de Le Boulch publicados no Brasil e que compõem o estudo feito para este ensaio.

As ideias de Le Boulch guiaram a atuação educativa de professores e influenciaram diversas obras na área de Educação Física. Dentre elas, podemos destacar a obra Educação de corpo inteiro: teoria e prática da Educação Física, de João Batista Freire. O livro teve grande influência na Educação Física, mas também nas áreas da Pedagogia e Psicologia, principalmente por se tratar de um trabalho voltado para estudantes de magistério, para professores da educação infantil (pré-escola) e professores do ensino fundamental anos iniciais (anteriormente denominadas de 1a a 4 a séries do $1^{\circ}$ grau) (FREIRE, 1989).

O contexto histórico no qual os trabalhos de Le Boulch integram as reflexões na área de Educação Física no Brasil remete aos anos 70 e 80 do século passado. Nesta época, 0 governo federal investiu na Educação Física com diretrizes baseadas no nacionalismo, na segurança nacional, na tentativa de formação de uma juventude forte e saudável. A legislação brasileira fundava a obrigatoriedade da prática de Educação Física em todos os níveis de ensino, pautando-se no esporte e na melhoria da aptidão física (BRASIL, 1997; SOUZA JÚNIOR, 2005).

Nesse período, algumas mudanças foram sendo configuradas na Educação Física, suscitando muitos embates na área. Em razão da qualificação de muitos professores, em especial daqueles que realizaram estudos de doutorado no exterior, desencadeiam-se muitos questionamentos sobre a realidade da Educação Física; bem como a criação de cursos de pósgraduação, a realização de congressos, o aumento do número de publicações e seminários na área. Registra-se ainda uma mudança no conteúdo das publicações, antes voltadas para áreas técnicas e biológicas. Temas como esporte, treinamento, desempenho e preparação física, por exemplo, foram gradativamente dividindo espaço com publicações voltadas para áreas das Ciências Sociais, com viés pedagógico, da Psicologia, Pedagogia e Sociologia, dentre outros (DAOLIO, 1998).

É nessa conjuntura que aparecem os movimentos renovadores e alternativos na Educação Física no Brasil, destacando-se entre eles a Psicomotricidade e a Psicocinética de Jean Le Boulch. Esses movimentos aportaram novas perspectivas para o conhecimento do

9 Livro publicado pela Universidade Federal de Uberlândia (UFB), 1983. 
corpo e do movimento humano para além da aptidão física, apresentando-se como contestação à Educação Física ligada ao esporte de rendimento e a uma concepção dualista do ser humano. Tal modelo não atendia mais os anseios da Educação Física na escola, sendo necessário ampliar a formação nessa área do ponto de vista epistemológico e metodológico (SOARES et al., 1992).

A Educação Física ganha impulso tanto pela ida de professores brasileiros ao exterior; bem como pela vinda ao Brasil do Dr. Jean Le Boulch, em dezembro de 1978, para ministrar um curso de Psicomotricidade, sob a coordenação da Secretaria de Educação Física e Desporto do Ministério da Educação (SEED/MEC) e dirigido especialmente para professores de Educação Física das Universidades Brasileiras, o que reforça o potencial das suas concepções para 0 desenvolvimento do pensamento da área (SOARES, 1996).

Essa concepção da obra de Le Boulch, segundo DARIDO (2003, p. 13), "[...] inaugura uma nova fase de preocupações para o professor de Educação Física que extrapola os limites biológicos e de rendimento corporal, passando a incluir e a valorizar o conhecimento de origem psicológica". A influência de seu trabalho voltado paraa Educação Físicae, mais especificamente, para 0 ambiente escolar, faz refletir sobre vários aspectos a respeito do desenvolvimento $\mathrm{e}$ aprendizagem das crianças, considerando as questões referentes à afetividade, às emoções e outras questões que envolviam elementos psicológicos e motores. Manuel Sérgio (1992), tecendo uma reflexão sobre a Ciência da Motricidade Humana e propondo perspectivas futuras para Educação Física, assinala a importância e influência dos trabalhos de Le Boulch na visão ampliada do corpo, ponto que consideramos primordial. A importância e influência das suas ideias na Educação Física no Brasil podem ser notadas, por exemplo, em sua participação no I Congresso Brasileiro de Educação Motora em 199410, onde proferiu a conferência de abertura. Evento importante para as reflexões que estimulavam os debates da área naquela época e que foi divulgado no livro Pensando a Educação Motora (DE MARCO, 1995).

É importante comentar que as obras de Le Boulch influenciaram a intervenção pedagógica e as pesquisas na área de Educação Física. Entretanto, após a década de 1980, houve uma lacuna na tradução e publicação de seus trabalhos no Brasil e um certo "esquecimento" das suas ideias. Dessa forma, seu trabalho não se expandiu no Brasil após esse período, mesmo que tenha figurado como influenciador e estivesse presente, mesmo que implicitamente, nos trabalhos voltados para a educação pelo movimento muito característico do pensamento da Educação Física Escolar vigente. Isso ocorreu, também, em detrimento de outras abordagens e conflitos que marcaram o ambiente da área nos anos 1980. Essas novas abordagens encontravam-se em consonância com as mudanças e uma "nova ordem" da Educação Física no Brasil daquele momento, não apenas no campo acadêmico, mas, também, político e social, apresentando outros direcionamentos e discussões para a área (DAOLIO, 1998).

Os conhecimentos advindos da Psicomotricidade influenciaram e influenciam até hoje a Educação Física no Brasil, percebemos em trabalhos como de Vítor da Fonseca (1983), na década de 1980, que apresenta contribuições para a Educação Física promovendo uma aproximação entre a Psicomotricidade terapêutica e a Educação Física, inclusive citando o trabalho de Le Boulch no tocante à impossibilidade de separação entre maturação e

10 LE BOULCH, Jean. O conceito de educação motora. Palestra proferida no I Congresso Brasileiro de Educação Motora. Coordenador: Ademir de Marco. Campinas, SP: Departamento de Educação Motora/FEF/Unicamp, 1994. VHS (80 min. aprox.). 
desenvolvimento na motricidade do ser humano, a relação corpo e o mundo; 0 ajustamento motor e a relação entre atitude e as praxias.

Considerando os conhecimentos da Psicomotricidade contidos nos trabalhos de Le Boulch que tiveram influência na Educação Física no Brasil, destacamos, no plano educativo, dentre outros, o de João Batista Freire, professor de Educação Física que teve um papel de destaque na área e que traz em seus trabalhos conhecimentos de psicomotricistas como Lappierre e Aucouturier. Estes, por sua vez, buscam uma conexão entre Psicomotricidade e educação, assim como na Teoria Psicocinética (LE CAMUS, 1986).

Freire (1989) traz uma crítica ao modelo escolar, ao modo como a Educação Física se apresentava na escola e sua característica intelectualista, trazendo uma proposta diferenciada dos padrões vigentes na época, principalmente no que se refere às propostas mecanicistas, à valorização dos padrões de comportamento e movimento, à busca por desempenho atlético e por desconsiderar o corpo, comuns naquele período. O livro apresenta-se como uma opção metodológica, caracterizando-se como uma pedagogia do movimento que deve considerar as particularidades do ser humano, especificamente 0 desenvolvimento centrado na própria criança, na necessidade de brincar, de jogar e de se conhecer; bem como a necessidade de se considerar nas aulas as experiências trazidas pelas crianças.

No livro de João Batista Freire há várias referências ao trabalho de Jean Le Boulch em consonância com a Psicocinética. Destacamos o estudo da sequência de desenvolvimento e evolução psicomotora ${ }^{11}$ e as questões referentes ao movimento humano, desde o início da vida, quando ainda são voluntários, quando há as primeiras expressões da vida da criança, passando a movimentos aprendidos e a possibilidade de ajustamentos e expressões intencionais desses movimentos no mundo. A função de interiorização, tratada nos trabalhos de Le Boulch, "[...] que permite a criança conscientizar-se de aspectos do seu corpo e exprimi-los verbalmente através da função simbólica" (FREIRE, 1989, p.34).

$\mathrm{Na}$ obra de Le Boulch observamos também a capacidade de relação entre o corpo e o meio ambiente, por meio do campo proprioceptivo, das sensações e da consciência das ações motoras (LE BOULCH, 2008). Destacamos também aspectos mais ligados ao âmbito da escola e ao trabalho do professor, como possibilidade de ensinar e consolidar funções psicomotoras nas crianças a partir dos exercícios de motricidade global. Também é relevante a importância de o professor proporcionar variadas experiências tanto para o aprendizado como para desenvolvimento; bem como o reconhecimento do valor das experiências sociais para o desenvolvimento afetivo, a consolidação da imagem do corpo, a confiança na capacidade e inteligência do corpo. Nessa construção de possibilidades de ensino sugere-se a prática de jogos e brincadeiras, a utilização de matérias variadas e brinquedos simbólicos e de imaginação, bem coerentes com os pressupostos da Psicocinética.

Melo (1998), baseado nas críticas e reflexões à Educação Física como componente curricular na escola e sua legitimação, buscou subsídios para o conhecimento do corpo e os processos de desenvolvimento do indivíduo. $\mathrm{O}$ autor considera a complexidade e indivisibilidade corporal, considerando fatores biológico, psicológico, social e cultural na construção de diretrizes para a atuação do professor de Educação Física. Assim, este poderia atuar numa perspectiva educativa na qual sua ação pedagógica pudesse contribuir para a compreensão do corpo próprio. Melo (1988) destaca também que no trabalho de Le Boulch os conhecimentos

11 Le Boulch, 1982. 
advindos da Psicomotricidade são ampliados para o contexto da Educação e da Educação Física, na condição de base pedagógica para o trabalho do professor. Neste sentido, destaca alguns pontos relevantes ao que se refere à percepção do corpo.

Le Boulch define a motricidade global, a educação perceptiva, a coordenação viso manual, a percepção e conhecimento de seu 'corpo próprio', o controle tônico, a descoberta e a tomada de consciência das diferentes partes do corpo, a orientação espacial o ritmo, entre outros, como aspectos que devem ser estimulados na ação pedagógica do professor de Educação Física nas séries iniciais de ensino, para que a criança construa, paulatinamente, sua consciência do corpo com base no vivido (MELO, 1998, p.55).

\section{CONSIDERAÇÕES FINAIS}

Os trabalhos de Le Boulch contribuem para pensar a Educação Física, em particular o conhecimento do corpo. Percebemos que no Brasil a teoria da Psicocinética foi por vezes confundida com a Psicomotricidade, área que forneceu subsídios a sua teoria, mas que foi devidamente diferenciada pelo próprio Le Boulch. Em entrevista concedida à revista Education Physique et Sport, em 1983, temos que:

- J. P. Cleuziou: Precisamente, esta é uma questão que muita gente se faz: o que é a psicocinética em relação à psicomotricidade?

- Jean Le Boulch: Tenho os mesmos pontos de vista com relação à psicomotricidade e com relação à educação física. Chamo sua atenção sobre o fato de que quando alguém diz: Faço psicomotricidade, é como se dissesse: eu faço educação física. É impossível saber exatamente qual é a natureza da sua ação. É necessário, então, ir mais além para buscar definições mais precisas. É por esta razão que eu não emprego jamais o termo psicomotricidade isoladamente, pois ele pode ter várias significações. Não se pode esquecer que a psicomotricidade nasceu sob o nome de 'reeducação psicomotora' nas clínicas de neuropsiquiatria infantil e particularmente em Salpêtrière. Desde então, sobretudo no âmbito da educação física, ela mantém sua marca de origem e quando alguém fala de psicomotricidade, relaciona-a a uma atividade inerente aos portadores de necessidades especiais (LE BOULCH, 1983b, p. 42).

Sobre as diferenças entre ambas, ele afirma:

Sua vocação, portanto, é terapêutica. Sua atividade está direcionada às criançasproblemas; eles permanecem, portanto, no eixo inicial da psicomotricidade reeducativa que, no entanto, sofreu mudanças importantes desde que a psicanálise se interessou por este domínio. É necessário frisar que as lutas doutrinais sobre este assunto estão tão vivas quanto na educação física. Particularmente, confrontam-se aqueles que permanecem no eixo da antiga reeducação, aqueles que adotam as terapias de inspiração psicanalítica, aqueles que seguem as terapias comportamentalistas. Pessoalmente, eu penso que estas práticas terapêuticas não deviam ser introduzidas na escola. Tratando dos saudáveis, corre-se o risco de transformá-los em doentes. Eu diferencio fundamentalmente os dois domínios: educação e terapia psicomotora. Eu não estou de acordo em que se misturem os gêneros (LE BOULCH, 1983b, p.42).

Os trabalhos de Le Boulch também foram criticados por essa "ligação" entre educação e terapia psicomotora pelo Coletivo de Autores (SOARES et al., 1992), considerada uma obra de referência ainda hoje na formação de professores de Educação Física na área escolar, que cita e tece crítica à Psicocinética. Mas reconhece o papel importante da teoria no cenário da 
Educação Física brasileira, no que diz respeito à concepção dualista do corpo na Educação Física, em uma perspectiva diversa das concepções vigentes nas décadas de 1960, 1970 e 1980. Os movimentos "renovadores", nos quais são colocados os trabalhos de Le Boulch, foram contrários aos métodos ginástico-militares, aos princípios do rendimento atlético e esportivo, à pedagogia tecnicista.

Destacamos a influência dos estudos de Le Boulch no Brasil, assim como a influência da Psicomotricidade na Psicocinética, afinal o autor também tinha formação naquela área e intencionou trazer os conhecimentos para a sua teoria e consequentemente para as ações educativas pensadas a partir dela. De forma resumida, destacamos como pontos relevantes da obra de Le Boulch aspectos como a consideração do movimento como meio na aprendizagem e desenvolvimento da pessoa; as relações entre fatores psíquicos e motores, considerando a afetividade, sexualidade e sua importância para a formação do ser humano; a compreensão de corpo e de esquema corporal como temas que constituem o conhecimento da Educação Física. Nesse cenário, o pensamento de Le Boulch apresenta-se como uma referência teórica e pedagógica que merece ser refletida, debatida e problematizada na formação de professores e nas pesquisas sobre o conhecimento do corpo.

\section{REFERÊNCIAS}

ALMEIDA, Felipe; BRACHT, Valter; GHIDETTI, Filipe. A presença da fenomenologia na educação física brasileira: implicações para o estudo do corpo e outras problematizações. Educación Fisica y Ciencia, v. 15, n. 2, p.1-16, 2013.

BRASIL. Secretaria de Educação Fundamental. Parâmetros curriculares nacionais: Educação física / Secretaria de Educação Fundamental. Brasília, 1997.

COLLINET, Collinet. Le Boulch: deux concepcions de L'Éducation Physique, deux periodes, deux doctrines. In: GLEYSE. Jacques et al. L'Éducation Physique au $\mathbf{x x}^{\mathrm{e}}$ siècle: Approches historique et culturelle. Paris: Vigot,1999.p. 29-58.

DAOLIO, Jocimar. Educação física brasileira: Autores e atores da década de 1980. Campinas, SP: Papirus, 1998.

DARIDO, Suraya Cristina. Educação Física na Escola: questões e reflexões. Rio de Janeiro: Guanabara Koogan, 2003.

DE MARCO, Ademir (Org.). Pensando a Educação Motora. Campinas, SP: Papirus, 1995.

FONSECA, V. Psicomotricidade. São Paulo: Martins Fontes, 1983.

FREIRE, João Batista. Educação de corpo inteiro: teoria e prática da Educação Física. São Paulo: Scipione, 1989.

GLEYSE, Jacques. Archéologie de l'éducation physique au XXe siècle en France. Paris: PUF, 1995.

LE BOULCH, Jean. Les facteurs de la valeur motrice : Analyse expérimentale de certains de ces facteurs. Interprétation d'un point de vue physiologique. 1960. $105 \mathrm{f}$. Thèse (Doctorat en médecine) Faculté Mixte de Médecine et de Pharmacie de Rennes, 1960. 
LE BOULCH, Jean. L'avenir d'une éducation physique scientifique. Les Cahiers scientifiques d'éducation physique, , n.1, p.12-21, 1961.

LE BOULCH, Jean. Vers une science du mouvement humain. Paris: Ed. EPS, 1971.

LE BOULCH, Jean. Introdução à Psicocinética. Lisboa: Semente, 1977.

LE BOULCH, Jean. 0 desenvolvimento psicomotor: do nascimento até os 6 anos. A Psicocinética na idade pré-escolar. Porto Alegre: Artmed, 1982.

LE BOULCH, Jean. A educação pelo movimento: a psicocinética na idade escolar. Porto Alegre: Artes Médicas, 1983.

LE BOULCH, Jean. Curso de psicomotricidade. Uberlândia: Universidade Federal de Uberlândia, 1983a.

LE BOULCH, Jean. Entretien avec Jean Le Boulch. La Revue de Éducation physique et Sport (EPS),n. 183, p.41- 49, sept./oct. 1983b.

LE BOULCH, Jean. Rumo a uma ciência do Movimento Humano. Porto Alegre: Artes Médicas, 1987.

LE BOULCH, Jean. Educação Psicomotora: a psicocinética na idade escolar. 2. ed. Porto Alegre: Artes Médicas, 1987 a.

LE BOULCH, Jean. O conceito de Educação Motora. In: DE MARCO, Ademir (Org.). Pensando a educação motora. Campinas, SP: Papirus, 1995.p.11- 26.

LE BOULCH, Jean. 0 corpo na escola no século XXI: Práticas corporais. São Paulo: Phorte, 2008.

LE CAMUS, Jean. 0 corpo em discussão: da reeducação motora às terapias de mediação corporal. Porto Alegre: Artes Médicas, 1986.

MELO, José Pereira. Desenvolvimento da consciência corporal: uma experiência da educação física na idade pré-escolar. Campinas/SP: Editora da Unicamp, 1998.

MERLEAU-PONTY, Maurice. La phénoménologie de la perception. Paris: Gallimard, 1945.

NÓBREGA, Terezinha Petrúcia; MENDES, Isabel; GLEYSE, Jacques. Compreensões de corpo na Educação Física: análise de conteúdo das Revistas EPS (França) e RBCE (Brasil). Revista Brasileira de Ciências do Esporte, v. 38, n. 3, p. 227-234, 2016.

NÓBREGA, Terezinha Petrúcia. Corpo e natureza em Merleau-Ponty. Movimento, v.20, n.3, p. 11751196, 2014.

SÉRGIO, Manuel. Motricidade humana: um paradigma emergente. In: MOREIRA, W.W. (Org.) Educação Física e Esportes: perspectivas para o século XXI. Campinas, SP: Papirus, 1993.p.91108.

SOARES, Carmem Lúcia. Educação Física Escolar: Conhecimento e Especificidade. Revista Paulista de Educação Física, sup. 2, p. 6-12, 1996.

SOARES. Carmen Lúcia. Educação Física: raízes europeias e Brasil. 3. ed. Campinas, SP: Autores Associados, 2004. 
SOARES, Carmen Lúcia et al. (Org.). Metodologia do ensino da Educação Física. São Paulo: Cortez, 1992.

SOUZA JÚNIOR, Marcílio. História da educação física escolar no Brasil. In: NÓBREGA, Terezinha Petrúcia da. (Org.). 0 ensino de educação física de $5^{\mathfrak{a}}$ a $8^{\mathrm{a}}$ séries: Livro didático. Natal: Paidéia, 2005. p. 13 - 32. 